\title{
Acute kidney injury due to acyclovir
}

\author{
Cigdem Yildiz $\cdot$ Yasemin Ozsurekci • \\ Safak Gucer $\cdot$ Ali Bulent Cengiz $\cdot$ Rezan Topaloglu
}

Received: 26 May 2012/ Accepted: 13 September 2012/Published online: 1 October 2012

(C) Japanese Society of Nephrology 2012

\begin{abstract}
Acyclovir is an antiviral agent widely used in herpetic infections in children. Although acyclovir is generally well tolerated, severe nephrotoxicity has been reported in some cases. In this report, we present a 16-yearold girl who developed acute renal failure due to acyclovir treatment and who needed repetitive hemodialysis. Renal biopsy was performed in order to confirm the diagnosis. A diagnosis of drug-related acute tubulointerstitial nephritis with focal tubular necrosis was made.
\end{abstract}

Keywords Acyclovir - Acute renal failure - Repetitive hemodialysis

\section{Introduction}

Acyclovir is an antiviral agent widely used in herpetic infections in children [1]. Although acyclovir is generally well tolerated, severe nephrotoxicity has been reported in some cases [2,3]. Acute kidney injury (AKI) secondary to acyclovir is characterized by a decrease in renal function that usually develops within $12-48 \mathrm{~h}$ of drug administration, as indicated by a rapid rise in the serum creatinine [4].

C. Yildiz $\cdot$ R. Topaloglu $(\bowtie)$

Department of Pediatric Nephrology and Rheumatology,

Hacettepe University Faculty of Medicine, Sihhiye,

Ankara 06100, Turkey

e-mail: rezantopaloglu@hacettepe.edu.tr

Y. Ozsurekci · A. B. Cengiz

Department of Pediatric Infectious Diseases,

Hacettepe University Faculty of Medicine, Ankara, Turkey

S. Gucer

Department of Pediatric Pathology,

Hacettepe University Faculty of Medicine, Ankara, Turkey
Dialysis may be needed in some severe cases [5]. Accurate diagnosis and effective treatment of AKI secondary to acyclovir is critical for successful management.

In this report, we present a 16-year-old girl who developed acute renal failure due to acyclovir treatment and who needed repetitive hemodialysis.

\section{Case report}

A 16-year-old girl presented to the emergency department () with a 10-day history of aphasia and a one-day history of convulsion. She had no fever or any signs of respiratory tract infection prior to admission. She was confused and did respond to verbal stimuli. Intravenous (IV) acyclovir $1500 \mathrm{mg} / \mathrm{m}^{2} /$ day in 3 divided doses was started for probable encephalitis. Serum creatinine $(\mathrm{Cr}: 0.6 \mathrm{mg} / \mathrm{dl})$ and blood urea nitrogen (BUN: $7.9 \mathrm{mg} / \mathrm{dl}$ ) levels were both normal. On the second day of treatment with acyclovir, she started to vomit 4-5 times a day, and her serum BUN and Cr levels increased to 56 and $7.2 \mathrm{mg} / \mathrm{dl}$, respectively. There was no history of risk factors of acyclovir-related AKI, including underlying renal insufficiency, dehydration, and regular medication. Additionally, there was no other condition leading to this rapid elevation of creatinine, such as rhabdomyolysis with any clinic and laboratory signs. IV acyclovir was stopped after 6 doses of IV acyclovir (cumulative dose: $4.8 \mathrm{~g}$ ). Urine specific gravity was 1010 , $100 \mathrm{mg} / \mathrm{dl}$ of proteinuria with 19 erythrocytes and 48 leucocytes/HPF. Urine sodium ( $\mathrm{Na}$ ) and $\mathrm{Cr}$ levels were 36 and $108.9 \mathrm{mg} / \mathrm{dl}$, respectively. Fractional $\mathrm{Na}$ excretion was $1.5 \%$, consistent with intrinsic renal failure. Urinary $\beta 2$ microglobuline level was significantly increased $(3357 \mathrm{mg} / \mathrm{dl}$, normal range 0-300). Hemodialysis was started, with an extremely rapid increase of serum creatinine from 0.6 to 


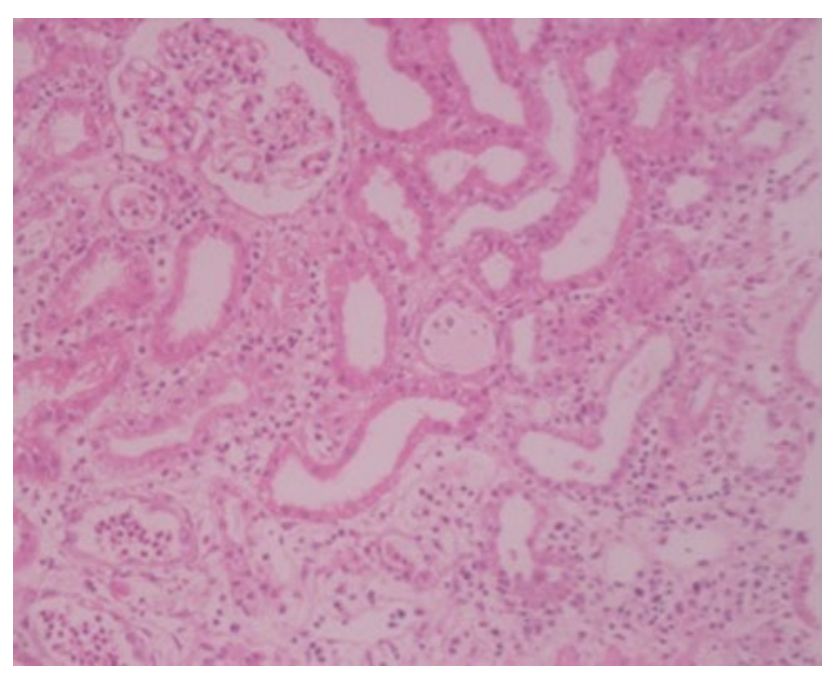

Fig. 1 Renal biopsy shows a moderate tubulointerstitial inflammation with marked edema. Note an unaffected glomerulus (upper right) and flattened tubules with apoptotic and inflammatory cells in their lumens (lower left)

$7.2 \mathrm{mg} / \mathrm{dl}$ on the next day, which was considered as a result of renal tubular injury (urinary $\beta 2$ microglobuline: $3357 \mathrm{mg} / \mathrm{dl}$, FeNa: $1.5 \%$; GFR: $23 \mathrm{ml} / \mathrm{min} / 1.73 \mathrm{~m}^{2}$ ). On the third day, oliguria had evolved. Additionally, ultrafiltration was performed because of oliguria (urine output $<1 \mathrm{ml} / \mathrm{kg} / \mathrm{h}$ ) signs of hypervolemia, and hypertension. Supportive treatment in order to maintain the homeostasis was given. She did not have any sign of uveitis. Other causes of AKI such as autoinflammatory diseases were eliminated. With suspected tubulointerstitial nephritis due to acyclovir, IV pulse prednisolone $(20 \mathrm{mg} / \mathrm{kg} /$ day $)$ was given on 3 consecutive days and daily hemodialysis was continued. Following the 3-day bolus treatment, oral steroid treatment $(1 \mathrm{mg} / \mathrm{kg} /$ day $)$ was commenced. Renal biopsy was performed in order to confirm the diagnosis. A moderate and patchy tubulointerstitial infiltration consisting of neutrophils, lymphocytes, histiocytes, plasma cells, few eosinophils, focal necrosis of cortical proximal tubules, and edema were noted. The 15 glomeruli appeared normal, with minimal increase in mesangial matrix. Necrotic tubules were filled with the apoptotic and acute inflammatory cells and occasional hyaline casts. Blood vessels were normal. Immunofluorescence microscopy was not informative. A diagnosis of drug-related acute tubulointerstitial nephritis with focal tubular necrosis was made (Fig. 1). On the 10th day of admission, the consciousness level of the patient was improved, and her serum Cr level decreased to $1.7 \mathrm{mg} / \mathrm{dl}$ (Fig. 2). The patient was discharged on the 20th day with improved neurological status and serum $\mathrm{Cr}$ level of $0.6 \mathrm{mg} / \mathrm{dl}$. The dose of prednisolone was tapered to $10 \mathrm{mg} /$ day and was eventually stopped. At her

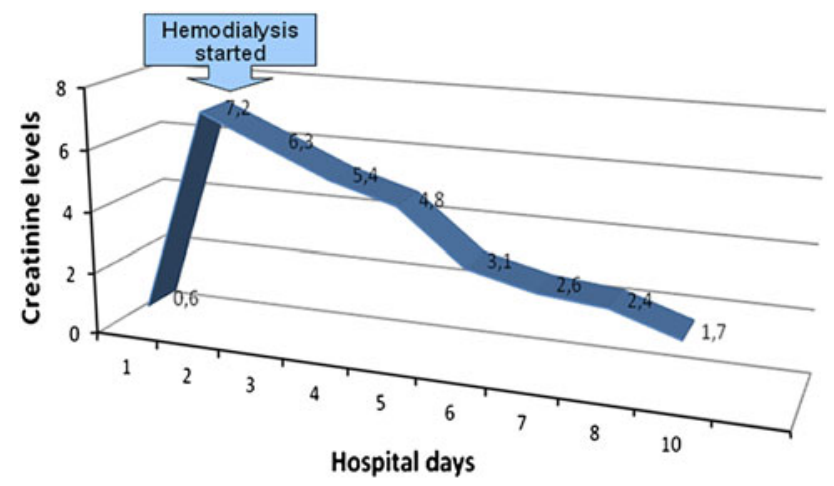

Fig. 2 Creatinine $(\mathrm{Cr})$ levels of the patient for the duration of hospitalization. In total, eight dialyses were performed for each level, except for the first value

last visit, her BUN and serum Cr levels were 10.6 and $0.6 \mathrm{mg} / \mathrm{dl}$, respectively.

Her repeated eye examinations were normal in regards to uveitis.

\section{Discussion}

Acyclovir is an important antiviral agent in the therapy of herpes simplex and varicella zoster virus infections [6]. Although the drug is well tolerated, severe nephrotoxicity, which often leads to acute renal failure, has been observed in patients [4, 7]. Acyclovir-induced renal failure occurs in approximately $12-48 \%$ of cases [4]. The optimal usage of acyclovir is very important in order to avoid its potentially life-threatening complications. Acyclovir-induced nephrotoxicity is typically evident by an increase in the plasma creatinine level, abnormal urine sediment, or acute renal injury [8]. Acyclovir is rapidly excreted in the urine via glomerular filtration and tubular secretion, and reaches high concentrations in the tubular lumen. Renal excretion of unchanged drug reaches approximately 60-90\% [7, 9, 10]. Acyclovir is relatively insoluble in the urine, particularly in the distal tubular lumen [7, 9-12]. Rapid intravenous administration of high-dose acyclovir is associated with high luminal concentrations of this drug and the intratubular precipitation of crystals can cause renal injury $[7,9,10]$. Typically, crystalluria develops within $24-48 \mathrm{~h}$ of the initiation of acyclovir therapy. Severe intraparenchymal precipitation of crystals can cause interstitial congestion and hemorrhage, leading to a decrease of renal blood flow [7, 10-12]. The serum creatinine levels of our patient also began to rise within $48 \mathrm{~h}$ of acyclovir treatment. Renal biopsy revealed no sign of precipitation of crystals. Clinical evidence of nephrotoxicity in the absence of crystalluria was suggested to be secondary to the direct cytotoxicity effect of the drug to tubular cells and acute 
interstitial nephritis in our patient, as mentioned in other studies $[8,13,14]$. Renal biopsy findings of patients with acyclovir toxicity include bulging of tubular cells, dilated tubular lumens, loss of proximal-distal tubular differentiation, flattening and vacuolization of epithelial cells, and epithelial cell mitoses $[8,14]$. A moderate and patchy tubulointerstitial infiltration of inflammatory cells and focal necrosis of cortical proximal tubules with edema were noted in our patient.

The administration of high doses of acyclovir $\left(\geq 1500 \mathrm{mg} / \mathrm{m}^{2}\right.$ per day) with other nephrotoxic agents, pre-existing renal disease, and dehydration play important roles in acyclovir nephrotoxicity [15]. Acyclovir dose should be reduced in patients with underlying renal insufficiency. Furthermore, slow drug infusion, over 1-2 h, adequate fluid replacement, and induction of high urinary flow rates $(100-150 \mathrm{ml} / \mathrm{h})$ should be encouraged in order to prevent crystal precipitation and subsequent tubular obstruction [7, 9-11, 16]. Despite vomiting 4-5 times a day as a predisposing factor for prerenal failure in our patient, she was adequately hydrated and no clinical evidence of hypovolemia was observed. Furthermore, any drug that causes nephrotoxicity was not used with acyclovir therapy.

The role of steroids still remains controversial in the treatment of drug-induced acute interstitial nephritis (DIAIN). Some studies have suggested a positive influence on the complete recovery of renal function in those patients who received steroids [17-19]. A multicenter study of González et al. [20] showed that, in biopsy-proven DI-AN patients, final creatinine levels were found to be better (lower) in the steroid administered group than in the nonsteroid (control) group. Also, according to that study, the final serum creatinine level and renal pathology were affected negatively if steroid treatment was started late ( 2 weeks after withdrawal of the presumed causative drug). In light of these data, steroid treatment was started in the present case, with an excellent outcome.

Finally, acyclovir dose should be reduced in patients with underlying renal insufficiency. The treatment of established renal failure includes the induction of diuresis with a loop diuretic in order to wash out obstructing crystals, detailed supportive care, and initiation of dialysis when indicated. Hemodialysis removes substantial amounts of acyclovir. Peritoneal dialysis is less effective and should not be used [8].

Our patient presented with severe acute renal failure and needed repetitive hemodialysis. We aimed to draw one's attention to the importance of the accurate diagnosis and effective treatment of AKI secondary to acyclovir toxicity.

Conflict of interest The authors have declared that no conflict of interest exists.

\section{References}

1. Bryson YJ. The use of acyclovir in children. Pediatr Infect Dis. 1984;3:345-8.

2. Genc G, Ozkaya O, Acikgöz Y, Yapici O, Bek K, Gülnar Sensoy $\mathrm{S}$, et al. Acute renal failure with acyclovir treatment in a child with leukemia. Drug Chem Toxicol. 2010;33:217-9.

3. Fleischer R, Johnson M. Acyclovir nephrotoxicity: a case report highlighting the importance of prevention, detection, and treatment of acyclovir-induced nephropathy. Case Report Med. 2010; 2010. pii: 602783.

4. Perazella MA. Crystal-induced acute renal failure. Am J Med. 1999;106:459-65.

5. Krieble BF, Rudy DW, Glick MR, Clayman MD. Case report: acyclovir neurotoxicity and nephrotoxicity-the role for hemodialysis. Am J Med Sci. 1993;305:36-9.

6. Al-Matter ER, Bourahma MH, Aboobacker KC. Acyclovir induced reversible renal failure in an immunocompromised child with extensive cutaneous herpes zoster. Kuwait Med J. 2004;36:47-8.

7. Keeney RE, Kirk LE, Bridgen D. Acyclovir tolerance in humans. Am J Med. 1982;73:176-81.

8. Ahmad T, Simmonds M, McIver AG, McGraw ME. Reversible renal failure in renal transplant patients receiving oral acyclovir prophylaxis. Pediatr Nephrol. 1994;8:489-91.

9. Sawyer MH, Webb DE, Balow JE, Straus SE. Acyclovir-induced renal failure. Clinical course and histology. Am J Med. 1988;84: 1067-71.

10. Brigden D, Rosling AE, Woods NC. Renal function after acyclovir intravenous injection. Am J Med. 1982;73:182-5.

11. Bean B, Aeppli D. Adverse effects of high-dose intravenous acyclovir in ambulatory patients with acute herpes zoster. J Infect Dis. 1985; 151:362-5.

12. Spiegal DM, Lau K. Acute renal failure and coma secondary to acyclovir therapy. JAMA. 1986;255:1882-3.

13. Becker BN, Fall P, Hall C, Milam D, Leonard J, Glick A, et al. Rapidly progressive acute renal failure due to acyclovir: case report and review of the literature. Am J Kidney Dis. 1993;22: $611-5$.

14. Vomiero G, Carpenter B, Robb I, Filler G. Combination of ceftriaxone and acyclovir - an underestimated nephrotoxic potential? Pediatr Nephrol. 2002;17:633-7.

15. Vachvanichsanong P, Patamasucon P, Malagon M, Moore ES. Acute renal failure in a child associated with acyclovir. Pediatr Nephrol. 1995;9:346-7.

16. Giustina A, Romanelli G, Cimino A, Brunori G. Low-dose acyclovir and acute renal failure. Ann Intern Med. 1988;108:312.

17. Galpin JE, Shinaberger JH, Stanley TM, Blumenkrantz MJ, Bayer AS, Friedman GS, et al. Acute interstitial nephritis due to methicillin. Am J Med. 1978;65:756-65.

18. Buysen JGM, Houthoff HJ, Krediet RT, Arisz L. Acute interstitial nephritis: a clinical and morphological study in 27 patients. Nephrol Dial Transplant. 1990;5:94-9.

19. Pusey CD, Saltissi D, Bloodworth L, Rainford DJ, Christie JL. Drug associated acute interstitial nephritis: clinical and pathological features and the response to high dose steroid therapy. Q J Med. 1983;52:194-211.

20. González E, Gutiérrez E, Galeano C, Chevia C, de Sequera P, Bernis C, et al. Early steroid treatment improves the recovery of renal function in patients with drug-induced acute interstitial nephritis. Kidney Int. 2008;73:940-6. 